
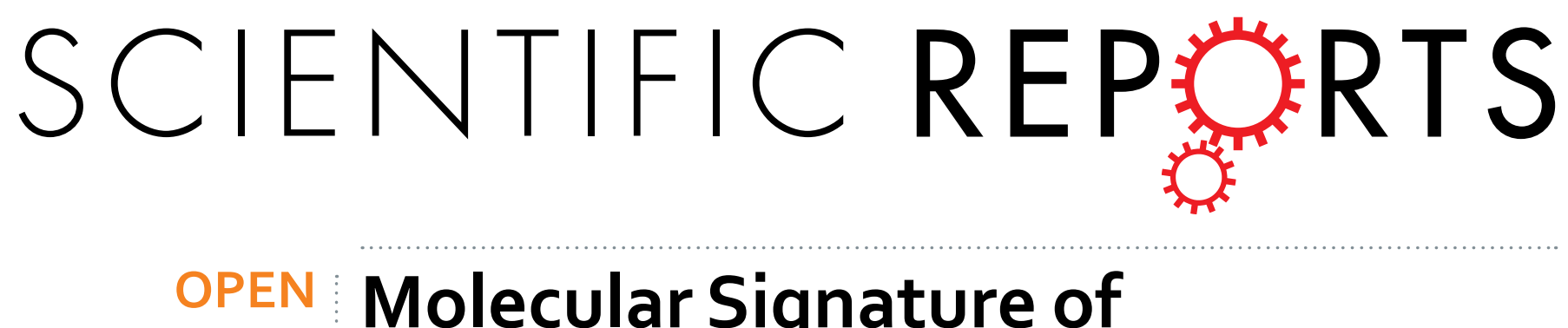

\title{
Molecular Signature of
}

Pseudomonas aeruginosa with Simultaneous Nanomolar

Received: 22 March 2016

Accepted: 27 June 2016

Published: 18 July 2016
Detection of Quorum Sensing
Signaling Molecules at a Boron-
Doped Diamond Electrode

Alyah Buzid ${ }^{1,2}$, Fengjun Shang ${ }^{1,2}$, F. Jerry Reen ${ }^{3}$, Eoin Ó Muimhneacháin ${ }^{2}$, Sarah L. Clarke ${ }^{2}$, Lin Zhou ${ }^{1,2}$, John H. T. Luong ${ }^{1,2}$, Fergal O'Gara ${ }^{3}$, Gerard P. McGlacken ${ }^{2}$ \& Jeremy D. Glennon ${ }^{1,2}$

Electroanalysis was performed using a boron-doped diamond (BDD) electrode for the simultaneous detection of 2-heptyl-3-hydroxy-4-quinolone (PQS), 2-heptyl-4-hydroxyquinoline (HHO) and pyocyanin (PYO). PQS and its precursor HHO are two important signal molecules produced by Pseudomonas aeruginosa, while $\mathrm{PYO}$ is a redox active toxin involved in virulence and pathogenesis. This Gramnegative and opportunistic human pathogen is associated with a hospital-acquired infection particularly in patients with compromised immunity and is the primary cause of morbidity and mortality in cystic fibrosis (CF) patients. Early detection is crucial in the clinical management of this pathogen, with established infections entering a biofilm lifestyle that is refractory to conventional antibiotic therapies. Herein, a detection procedure was optimized and proven for the simultaneous detection of $\mathrm{PYO}, \mathrm{HHO}$ and POS in standard mixtures, biological samples, and $P$. aeruginosa spiked CF sputum samples with remarkable sensitivity, down to nanomolar levels. Differential pulse voltammetry (DPV) scans were also applicable for monitoring the production of PYO, $\mathrm{HHO}$ and POS in P. aeruginosa PA14 over $8 \mathrm{~h}$ of cultivation. The simultaneous detection of these three compounds represents a molecular signature specific to this pathogen.

Bacterial species rely on a wide array of signaling molecules, signal detection systems, and signal-transduction mechanisms to coordinate gene regulation ${ }^{1}$. Quorum sensing (QS) is a cell-to-cell communication system, which involves the production and detection of diffusible signaling molecules, known as 'autoinducers' or bacterial pheromones ${ }^{1,2}$. Chemically diverse QS signaling molecules ranging from $\mathrm{N}$-acyl homoserine lactones (AHLs) and 2-alkyl-4-quinolones (AHQs) to peptides and furanones, coordinate activities including bacterial secondary metabolite production, biofilm development, bioluminescence, competence, plasmid transfer and pathogenicity ${ }^{2,3}$. Pseudomonas aeruginosa, a Gram-negative opportunistic pathogen, is capable of surviving in a broad range of natural environments. It is an antibiotic-resistant human pathogen associated with hospital-acquired infections ${ }^{4}$ and causes acute pneumonia and chronic lung infections in cystic fibrosis (CF) patients ${ }^{5}$. Two AHL-based systems (the las and $r h l$ ) together with the AHQ-based system form a complex QS hierarchy in $P$. aeruginosa which controls global gene expression ${ }^{6}$. The primary P. aeruginosa AHQ signaling molecules are 2-heptyl-3-hydroxy-4-quinolone 1 ("Pseudomonas Quinolone Signal", PQS) and its immediate precursor, 2-heptyl-4-hydroxyquinoline 2 (HHQ) ${ }^{7}$. Pyocyanin 3 (1-hydroxy-N-methylphenazine, PYO), one of the several phenazine-based secretory products of $P$. aeruginosa (Fig. 1), is also involved in $\mathrm{QS}^{8}$. PYO is also considered as

${ }^{1}$ Innovative Chromatography Group, Irish Separation Science Cluster (ISSC), Ireland. ${ }^{2}$ Department of Chemistry and Analytical \& Biological Chemistry Research Facility (ABCRF), University College Cork, Ireland. ${ }^{3}$ BIOMERIT Research Centre, Department of Microbiology, University College Cork, Ireland. Correspondence and requests for materials should be addressed to J.D.G. (email: j.glennon@ucc.ie) 


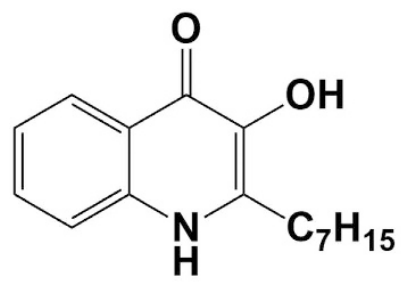

1

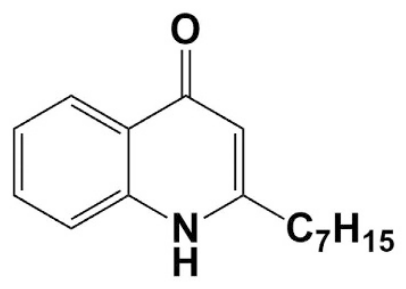

2<smiles>Cn1c2cccc(=O)c-2nc2ccccc21</smiles>

3

Figure 1. The structure of $P$. aeruginosa AHQ and PYO signals.

an important virulence and pro-inflammatory factor. As a redox-active molecule, PYO is a potential source of damaging reactive species, which plays a significant role in oxidative stress and inducing lung injury infected by $P$. aeruginosa. In general, $P$. aeruginosa is the only species known to produce PQS and PYO while HHQ can be generated by Burkholderia strains ${ }^{9}$. Also, the lack of these molecules does not mean that $P$. aeruginos $a$ is absent, since certain isolates lack a functioning AHQ system (e.g. P. aeruginosa PA7) ${ }^{10}$.

Among different analytical methods for AHQs and PYO detection, an LC-MS/MS method was developed to profile a broad range of QS signaling molecules including PQS and $\mathrm{HHQ}^{3}$. The PYO levels of patient sputa ranging from 0 to $27.3 \mu \mathrm{g} \mathrm{mL}^{-1}$ were detected by HPLC- UV detection ${ }^{11}$. Chromatography can be paired with mass spectrometry to enhance detection sensitivity, however, this approach requires sample pretreatment, lengthy analysis times and high costs, whereas fluorometry is sample-consuming and lacks selectivity ${ }^{12}$. Accurate and rapid point-of-care diagnosis has stimulated efforts to develop simple and sensitive electrochemical strategies. Biosensor-based assays for PQS and HHQ have been reported ${ }^{2,13,14}$ in addition to simple cyclic voltammetry (CV) and amperometry using a boron-doped diamond (BDD) thin-film electrode as an excellent method for the detection of HHQ, PQS ${ }^{15}$ and 2-(2-hydroxyphenyl)-thiazole-4-carbaldehyde (IQS) ${ }^{16}$. Adsorptive stripping voltammetry (AdSV) using a hanging mercury drop electrode (HMDE) ${ }^{17}$ and differential pulse voltammetry (DPV) using graphite rods ${ }^{18}$ were employed for PYO detection in biological samples. Disposable screen-printed electrodes were also used to probe the presence of PYO in the human biofluids by square wave voltammetry (SWV $)^{19-21}$. Sismaet $e t$ al. measured the production of PYO in the presence of various amino acids. The presence of the amino acids resulted in a faster and stronger electrochemical response ${ }^{22}$. Kim et al. ${ }^{23}$ developed a bio-based redox capacitor for in situ monitoring of the production of PYO during P. aeruginosa cultivation. The catechol-grafted chitosan film amplified the electrochemical signals of PYO and lowered the detection limit. Miniaturized PYO sensors in the form of a 'smart-bandage ${ }^{24,25}$ or 'nanofluidic ${ }^{8,26}$ were also reported. There are, however, only two reports on the simultaneous electrochemical determination of $\mathrm{PQS}$ and $\mathrm{PYO}^{27,28}$. In the former, a conductive polymer film modified glassy carbon electrode has been applied to increase electroactive electrode surface. In the latter approach, a P. aeruginosa strain was grown on the electrode surface to concentrate electrochemical signals of PYO and PQS.

The BDD thin-film electrode ${ }^{29,30}$ featuring a wide potential range, high current density, extreme electrochemical stability, low background current and high resistance to fouling has proven promising for PQS detection ${ }^{15}$. This report unravels the use of a BDD electrode, without modification, for simultaneous determination of PYO, $\mathrm{PQS}$ and HHQ in a mixed solution. The influence of electrolyte $\mathrm{pH}$ on the peak potential separation and peak currents was also investigated. The optimized procedures were then applied to analyze supernatant extracts from $P$. aeruginosa wild-type strains, monitor the production of signaling molecules in the bacterial strain PA14 and detect the signals in CF patient sputa cultured with $P$. aeruginosa using a bare BDD electrode, taking advantages of the hydrogen surface termination and $\mathrm{sp}^{3}$ carbon bonding without the extended $\pi$-electron system for sensitive detection over other solid electrodes.

\section{Results and Discussion}

Electrochemical behavior of PQS, HHQ, and PYO. The redox reactions of $\mathrm{PYO}$ and the quinolones on the BDD electrode were studied by CV. The CV obtained for PQS at pH 5.0 on the pristine BDD electrode exhibited three oxidation peaks at $+0.759 \mathrm{~V},+1.103 \mathrm{~V}$ and $+1.590 \mathrm{~V}$ (Fig. 2a). In contrast, only one well-defined peak at $+1.351 \mathrm{~V}$ was observed on the CV of HHQ (Fig. 2b), indicating the simultaneous voltammetric measurements of the quinolones is feasible due to the peak potential differentiation. The CV of PYO (Fig. 2c) presented a pair of redox peaks (oxidation at $-0.1 \mathrm{~V}$ and reduction at $-0.153 \mathrm{~V}$ ) at the negative potential range, making these potentials unique for the identification/determination of PYO. PYO also provoked an oxidation peak at $+0.871 \mathrm{~V}$, resulting in a peak separation $(\Delta \mathrm{Ep})$ of $112 \mathrm{mV}$ to the first oxidation peak of PQS $(+0.759 \mathrm{~V})$. DPV was chosen for further experiments as a sensitive technique with good distinction against the background current.

Effect of electrolyte $\mathrm{pH}$ on the detection of $\mathrm{PYO}, \mathrm{HHO}$, and $\mathrm{PQS}$. The influence of electrolyte $\mathrm{pH}$ on the peak potentials (Ep) and peak currents (Ip) of the electrooxidation of PYO, HHQ and PQS was investigated by DPV in the $\mathrm{pH}$ range of 4.0 to 7.0. As illustrated in Fig. 3a, the anodic peak potential for the oxidation of PYO shifted to negative values when increasing the buffer $\mathrm{pH}$ with linear regression of $\mathrm{Ep}(\mathrm{V})=0.137-0.0551$ $(\mathrm{pH})$, indicating the role of protons in the oxidation process ${ }^{31}$. The determined slope was $55.1 \mathrm{mV} / \mathrm{pH}$, close to the reported value of $61 \mathrm{mV} / \mathrm{pH}^{27}$ and the expected value of $59 \mathrm{mV} / \mathrm{pH}$. Such behavior confirmed the number of hydrogen ions was equal to electrons taking part in the electrode reaction. The peak current (Ip) was 

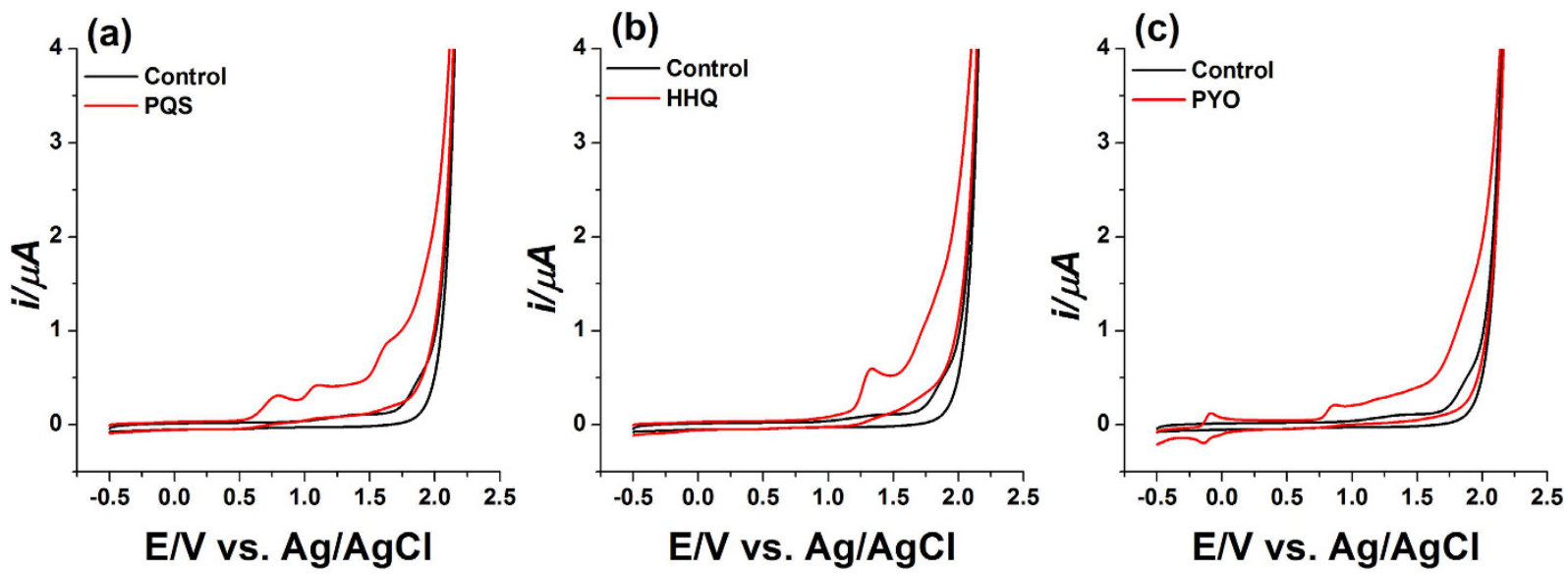

Figure 2. CV of (a) $50 \mu \mathrm{M}$ PQS; (b) $50 \mu \mathrm{M}$ HHQ; and (c) $10 \mu \mathrm{M}$ PYO at $100 \mathrm{mV} \mathrm{s}^{-1}$ in $50 \mathrm{mM}$ acetate buffer at pH 5.0 containing $20 \% \mathrm{ACN}$ on the BDD electrode vs. Ag/AgCl. The black lines represent blank $50 \mathrm{mM}$ acetate buffer at $\mathrm{pH} 5.0$ containing $20 \% \mathrm{ACN}$.
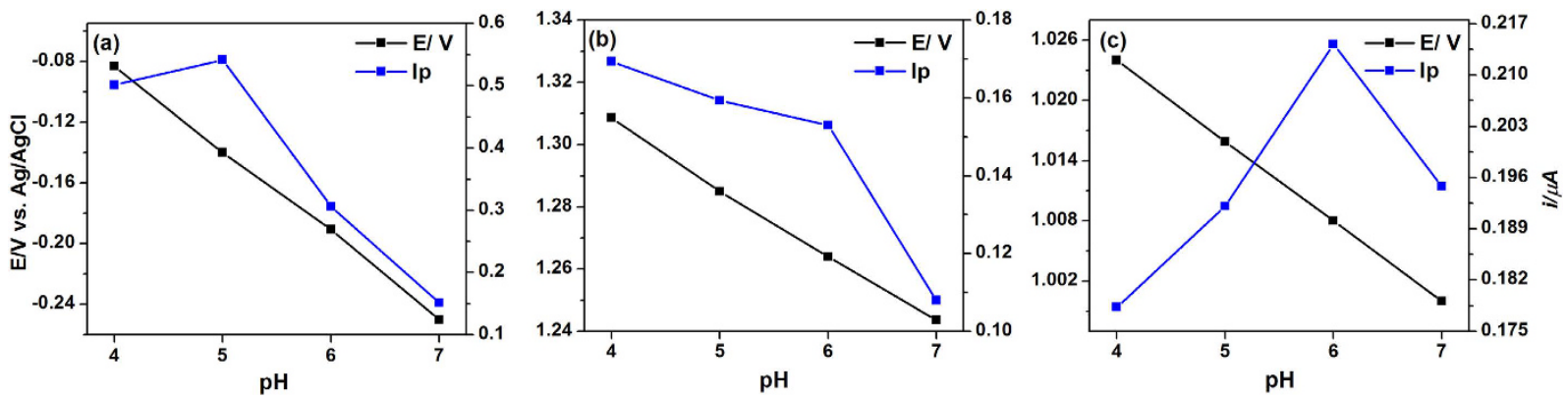

Figure 3. The effect of $\mathrm{pH}$ on the peak potential and peak current. DPV response the effect of $\mathrm{pH}(4.0$ to 7.0$)$ on the peak potential (Ep) and peak current (Ip) towards (a) $5 \mu \mathrm{M}$ PYO; (b) $20 \mu \mathrm{M}$ HHQ; and (c) $20 \mu \mathrm{M}$ PQS on the BDD electrode vs. Ag/AgCl.

also dependent on $\mathrm{pH}$, which increased when the electrolyte $\mathrm{pH}$ decreased from 7.0 to 4.0. As protonation was involved in the catalytic reactions, the electrocatalytic oxidation of $\mathrm{PYO}$ became more favorable at lower $\mathrm{pH}^{32}$ thus resulting in higher peak current. However, the oxidation peak of $\mathrm{PYO}$ at $\mathrm{pH} 4.0$ was $3.16 \%$ broader compared to the sharp peaks obtained at $\mathrm{pH}$ 5.0. The peak current intensity was decreased by increasing the $\mathrm{pH}$ to 6.0 and 7.0. The effect of buffer $\mathrm{pH}$ on the response of HHQ (Fig. 3b) and PQS (Fig. 3c) was investigated over the pH range 4.0 to 7.0. As a result of increasing $\mathrm{pH}$, the peak potential shifted to less positive values.

Figure 4 shows the DPVs for a ternary solution mixture of PYO, PQS and HHQ obtained with varying buffer $\mathrm{pH}$. All the oxidation peaks of PQS and HHQ shifted to less positive values in the potential range of $+0.5 \mathrm{~V}$ to $+1.5 \mathrm{~V}$ and the oxidation peak of $\mathrm{PYO}$ shifted to more negative values in the potential range of $-0.8 \mathrm{~V}$ to $-0.25 \mathrm{~V}$ when increasing the $\mathrm{pH}$ from 4.0 to 7.0. The DPVs obtained at $\mathrm{pH} 5.0$ and 6.0 exhibited five well-defined anodic peaks, whereas partially overlapped peaks of the biomarkers were observed in the voltammograms obtained at $\mathrm{pH} 4.0$ and 7.0. The peak separations of $\mathrm{PYO}$ and $\mathrm{PQS}$ in the potential range of $+0.65 \mathrm{~V}$ to $+1.15 \mathrm{~V}$ were $138.9 \mathrm{mV}, 176.2 \mathrm{mV}, 170.5 \mathrm{mV}$ and $161.1 \mathrm{mV}$ for $\mathrm{pH} 4.0,5.0,6.0$ and 7.0, respectively. The peak positions of the analytes might be attributed to different electrochemical activities of their functional groups on the electrode surface $^{33}$. Similar to PYO, the oxidation peak currents of PQS and HHQ decreased with elevated $\mathrm{pH}$. Therefore, considering the peak potential resolution and detection sensitivity, pH 5.0 acetate buffer $(50 \mathrm{mM})$ was chosen as the optimal medium.

Individual determination of PYO, PQS and HHO. Considering sufficient peak potential difference and superb detection sensitivity in individual determinations, a series of studies was then performed to verify the feasibility of selective detection of PQS, HHQ and PYO by DPV using the BDD electrode. Experiments were carried out by changing the concentration of the target analyte whilst maintaining those of the other two species constant. Figure 5a shows the DPV response of PYO at different concentrations $(2-100 \mu \mathrm{M})$ while PQS and HHQ were constant at $20 \mu \mathrm{M}$ and $10 \mu \mathrm{M}$, respectively. The peak potential of PYO at $-0.14 \mathrm{~V}$ remained unchanged when varying the concentrations of the compound. The current intensities of the oxidation peaks raised proportionally to increasing PYO concentration, in the range of $2-100 \mu \mathrm{M}$ with good linearity $\left(\mathrm{R}^{2}=0.991\right.$, Fig. $\left.5 \mathrm{~b}\right)$. The peak currents of PQS and HHQ decreased slightly without significant loss of electrocatalytic activities, due to the irreversible adsorption of the oxidation products on the electrode surface which hindered the further oxidation 


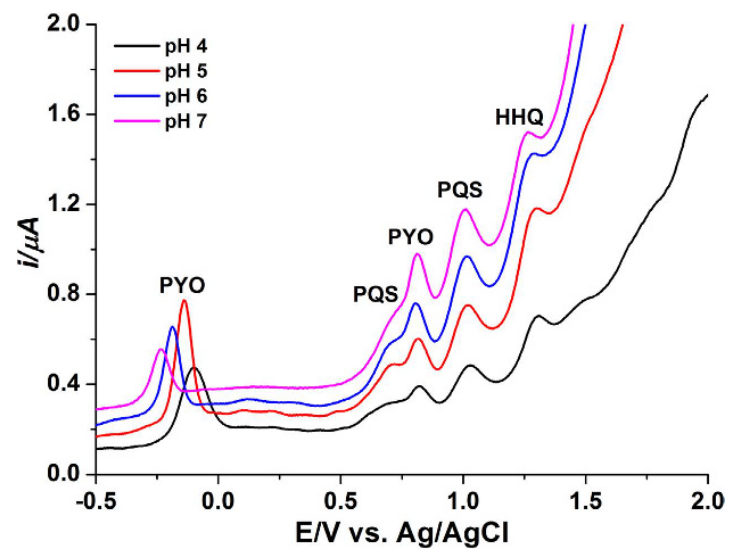

Figure 4. DPV of the ternary mixture of $5 \mu \mathrm{M}$ PYO, $20 \mu \mathrm{M}$ PQS and $20 \mu \mathrm{M} H \mathrm{HQ}$ at $\mathrm{pH} 4.0$ to 7.0 on the BDD electrode vs. Ag/AgCl.
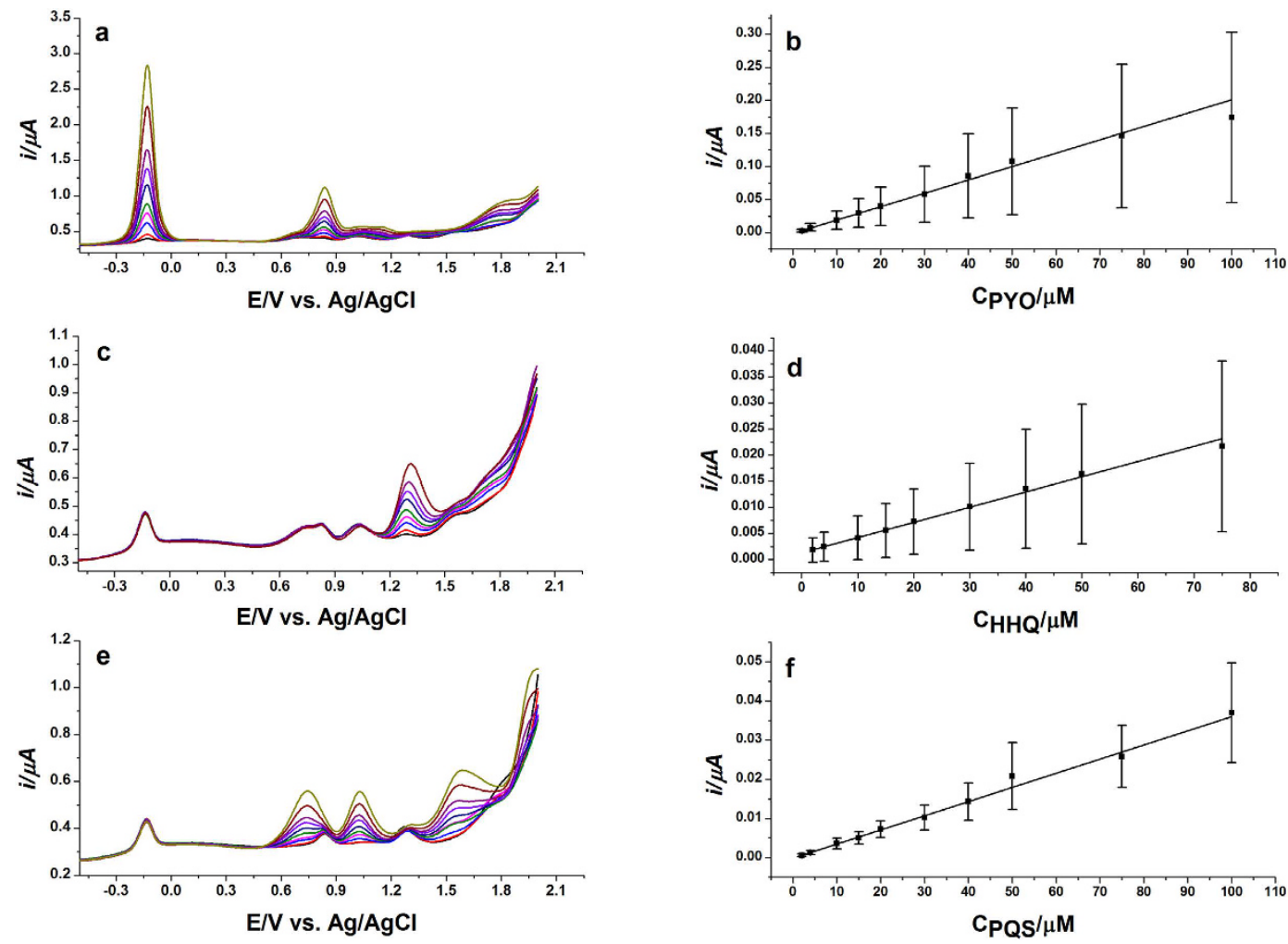

Figure 5. Calibration curve of PYO, HHQ and PQS. (a) DPVs of various PYO concentrations $(1-100 \mu \mathrm{M})$ containing $10 \mu \mathrm{M}$ HHQ and $20 \mu \mathrm{M}$ PQS; (b) Calibration plot obtained from DPVs recording shown in (a); (c) DPV s of various HHQ concentrations $(2-75 \mu \mathrm{M})$ containing $5 \mu \mathrm{M}$ PYO and $20 \mu \mathrm{M}$ PQS; (d) Calibration plot obtained from DPVs recording shown in (c); (e) DPVs of various PQS concentrations $(1-100 \mu \mathrm{M})$ at BDD containing $5 \mu \mathrm{M}$ PYO and $10 \mu \mathrm{M}$ HHQ; (f) Calibration plot obtained from DPVs recording shown in (e); Using the BDD electrode vs. $\mathrm{Ag} / \mathrm{AgCl}$ in $50 \mathrm{mM}$ acetate buffer, $\mathrm{pH} 5.0$ containing $20 \% \mathrm{ACN}$. Error bars correspond to standard deviation $(\mathrm{SD})(\mathrm{n}=3)$.

of PQS and HHQ on the electrode surface ${ }^{34}$. Similarly, Fig. $5 c$ displays the DPV calibration of HHQ in the presence of PYO and PQS exhibiting satisfactory linearity in the range of $2-75 \mu \mathrm{M}\left(\mathrm{R}^{2}=0.997\right.$, Fig. $\left.5 \mathrm{~d}\right)$. Also, Fig. 5e depicts the DPV calibration of PQS in the presence of PYO and HHQ demonstrating acceptable linearity in the range of $2-100 \mu \mathrm{M}\left(\mathrm{R}^{2}=0.996\right.$, Fig. $\left.5 \mathrm{f}\right)$. The oxidation peak of $\mathrm{PQS} \sim+1.0 \mathrm{~V}$ was selected for calibration. The analytical parameters for simultaneous determination of PYO, HHQ and PQS are present in Table 1 . The analytical performance of the BDD electrode using DPV is compared with the literature methods in Table 2. The effect of the $\mathrm{pH}$ and potential to obtain a lower limit of detection of PYO, HHQ and PQS are also investigated using amperometric measurement $(I / t)$ and compared to DPV on the BDD electrode in Table 3. In the case of PQS and 


\begin{tabular}{|c|c|c|c|c|c|}
\hline Analytes & $\begin{array}{l}\text { Linear range } \\
(\mu \mathrm{M})\end{array}$ & $\begin{array}{c}\text { Linear regression } \\
\text { equation }(\mathrm{I}: \mu \mathrm{A}, \mathrm{C}: \mu \mathrm{M})\end{array}$ & $\begin{array}{c}\text { Correlation } \\
\text { coefficient }\left(\mathbf{R}^{2}\right)\end{array}$ & $\begin{array}{l}\text { R.S.D \% } \\
(\mathbf{n}=3)^{\mathrm{a}}\end{array}$ & $\begin{array}{l}\text { Limit of detections } \\
\text { (LODs) }\end{array}$ \\
\hline PYO & $2-100$ & $\begin{array}{c}\mathrm{I}_{\text {pyo }}=2.019 \times 10^{-9} \\
\mathrm{C}-1.190 \times 10^{-9}\end{array}$ & 0.991 & 1.73 & $50 \mathrm{nM}$ \\
\hline HHQ & $2-75$ & $\begin{array}{c}\mathrm{I}_{\mathrm{HHQ}}=2.913 \times 10^{-10} \\
\mathrm{C}+1.278 \times 10^{-9}\end{array}$ & 0.996 & 2.45 & $250 \mathrm{nM}$ \\
\hline PQS & $2-100$ & $\begin{array}{c}\mathrm{I}_{\mathrm{PQS}}=3.615 \times 10^{-10} \\
\mathrm{C}-1.78 \times 10^{-10}\end{array}$ & 0.995 & 1.18 & $250 \mathrm{nM}$ \\
\hline
\end{tabular}

Table 1. Calibration curve and limit of detection using DPV at the BDD electrode. ${ }^{a}$ R.S.D (\%) calculated from triplicated DPV measurements for the potential at $20 \mu \mathrm{M}$ each of PYO, HHQ, and PQS $(\mathrm{n}=3) .{ }^{\mathrm{b}} \mathrm{LOD}$ $(S / N=3)$.

\begin{tabular}{|c|c|c|c|c|c|}
\hline Method & Analyte & $\begin{array}{l}\text { Linear range } \\
(\mu \mathrm{M})\end{array}$ & $\begin{array}{c}\text { Correlation coefficient } \\
\left(\mathbf{R}^{2}\right)\end{array}$ & $\begin{array}{r}\text { Detection } \\
\text { limit (nM) }\end{array}$ & Reference \\
\hline \multirow{3}{*}{$\mathrm{BDD}$} & PYO & $2-100$ & 0.991 & $50 \mathrm{nM}$ & \multirow{3}{*}{ Present work } \\
\hline & HHQ & $2-75$ & 0.996 & $250 \mathrm{nM}$ & \\
\hline & PQS & $2-100$ & 0.995 & $250 \mathrm{nM}$ & \\
\hline BDD & PQS & $0.1-5.5$ & 0.999 & $1 \mathrm{nM}$ & 15 \\
\hline HMDE & PYO & $0.002-0.3$ & 0.99 & $2 \mathrm{nM}$ & 17 \\
\hline Catechol-chitosan/Gold electrode & PYO & $0.1-1$ & N.R & $50 \mathrm{nM}$ & 22 \\
\hline Carbon fibre tow & PYO & $1-100$ & 0.998 & $30 \mathrm{nM}$ & 24 \\
\hline NEAs/Gold electrode ${ }^{\mathrm{b}}$ & PYO & $0-100$ & 0.96 & $441 \mathrm{nM}$ & 26 \\
\hline NEAs/Gold electrode & PYO & $1-100$ & 0.941 & $597 \mathrm{nM}$ & 8 \\
\hline
\end{tabular}

Table 2. Comparison of the proposed method on the BDD electrode using DPV with the literature

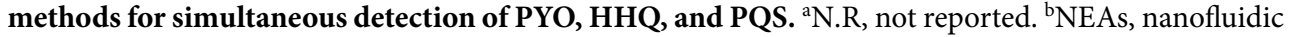
electrode assemblies.

\begin{tabular}{|c|c|c|c|c|c|c|c|}
\hline Analyte & $\begin{array}{c}0.8 \mathrm{~V}, \mathrm{I} / t \\
\mathrm{pH} 2.0\end{array}$ & $\begin{array}{c}1.0 \mathrm{~V}, \mathrm{I} / \mathrm{t} \\
\mathrm{pH} 2.0\end{array}$ & $\begin{array}{c}1.2 \mathrm{~V}, \mathrm{I} / t \\
\mathrm{pH} 2.0\end{array}$ & $\begin{array}{c}0.8 \mathrm{~V}, I / t \\
\mathrm{pH} 5.0\end{array}$ & $\begin{array}{c}1.0 \mathrm{~V}, \mathrm{I} / \mathrm{t}, \\
\mathrm{pH} 5.0\end{array}$ & $\begin{array}{c}1.2 \mathrm{~V}, \mathrm{I} / \mathrm{t} \\
\mathrm{pH} 5.0\end{array}$ & $\begin{array}{l}\text { DPV, } \\
\text { pH } 5.0\end{array}$ \\
\hline PYO & $600 \mathrm{nM}$ & $40 \mathrm{nM}$ & - & $400 \mathrm{nM}$ & $40 \mathrm{nM}$ & - & $50 \mathrm{nM}$ \\
\hline HHQ & $200 \mathrm{nM}$ & - & $16 \mathrm{nM}$ & $32000 \mathrm{nM}$ & - & $160 \mathrm{nM}$ & $250 \mathrm{nM}$ \\
\hline PQS & $1 \mathrm{nM}$ & - & - & $32 \mathrm{nM}$ & - & - & $250 \mathrm{nM}$ \\
\hline
\end{tabular}

Table 3. Comparison of the limit of detection of the three signals between DPV and $I / t$ curve on the BDD electrode.

HHQ, there are two parameters that can result in lower LOD; the $\mathrm{pH}$ and the oxidation potential, for example, pH 2.0 gives sensitive LOD at $+0.8 \mathrm{~V}$ and $+1.2 \mathrm{~V}$ for PQS and HHQ, respectively. While in the PYO case, the oxidation potential at $+1.0 \mathrm{~V}$ can result in lower LOD at either $\mathrm{pH}$.

Analysis of $P$. aeruginosa PA14 cultures, growth curves and clinical sample analysis. The optimized method on DPV was initially applied to the analysis of cell-free culture (supernatant) extracts of $P$. aeruginosa PA14 and pqsA mutant. DPV of the biological sample extracts were recorded by diluting the samples into $50 \mathrm{mM}$ acetate buffer ( $\mathrm{pH} 5.0$ ) containing $20 \% \mathrm{ACN}$. As expected, no analytes were detected from the supernatant of $P$. aeruginosa pqsA mutant. Nevertheless, $P$. aeruginosa PA14 produced a significant amount of PYO, in addition to the presence of PQS and HHQ (Fig. 6a). The concentration of PYO, HHQ and PQS measured in the cell-free extract of microbial strain PA14 were $37.03 \pm 0.76 \mu \mathrm{M}, 4.48 \pm 0.43 \mu \mathrm{M}$, and $11.17 \pm 0.15 \mu \mathrm{M}$, respectively $(\mathrm{n}=3)$.

Subsequently, a time-course analysis was performed using the BDD electrode to monitor the real-time concentration profiles of the three target molecules from early log phase into the stationary phase of growth. Cultures were sampled at $1 \mathrm{~h}$ intervals from the mid-log phase and monitored as before. Consistent with the established kinetics of signal production in P. aeruginosa, HHQ was initially identified at the highest concentration ${ }^{35,36}$, not surprising given that it is the precursor to PQS (Fig. 6b) ${ }^{37}$. As the cells entered stationary phase, both PQS and $\mathrm{PYO}^{38}$ become more abundant, with HHQ levels markedly reduced at $8 \mathrm{~h}$ (Fig. 6c,d).

CF sputum is a complex mixture of airway mucus glycoproteins, serum, proteins, DNA, alginate, and rigidifying lipids as well as inflammatory substances including polymorphonuclear leukocytes, antibodies, antimicrobial peptides, and dead host cells. Also, CF sputum samples are more viscous than normal samples as a result of negatively charged biopolymers (mucin, DNA, and alginate) which are connected through noncovalent interactions such as electrostatic, hydrogen, and hydrophobic bonding. All these matrix constituents protect the epithelial cells and form a diffusion barrier for pathogen and harmful particles ${ }^{39,40}$. In order to evaluate the extent of matrix 


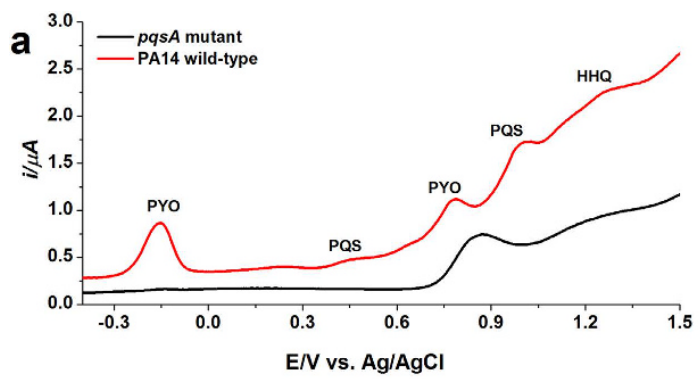

b<smiles>Nc1ccccc1C(=O)O</smiles>

c

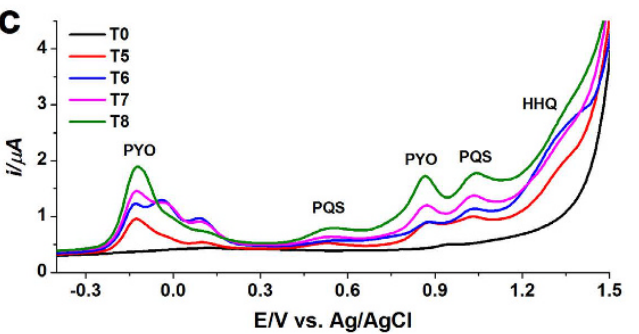

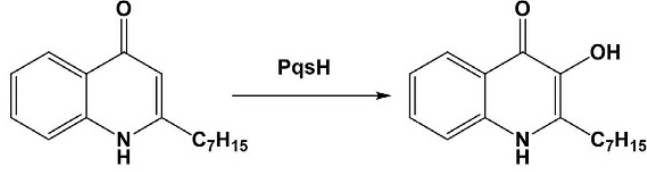

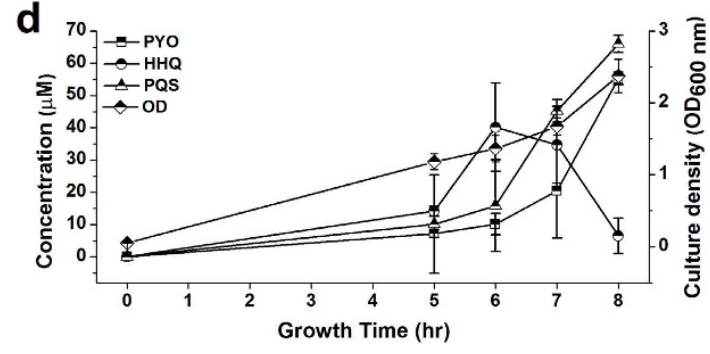

Figure 6. Bacterial cell-free culture PA14 analysis, HHQ and PQS biosynthesis routine and HHQ, PQS and PYO production kinetics in PA14. (a) DPVs of P. aeruginosa PA14 wild-type and $p q s A$ mutant in LB media grown for $7 \mathrm{~h}$ at $37^{\circ} \mathrm{C}$ with $\mathrm{OD}_{600 \mathrm{~nm}}$ of 2.4 and 2.1 for the PA14 wild-type and $p q s A$ mutant, respectively. The cell-free culture was extracted twice with acidified ethyl acetate and a given amount of the reconstituted sample added to the electrolyte: $50 \mathrm{mM}$ acetate buffer, pH 5.0 with $20 \%$ ACN. Detection on the BDD electrode vs. Ag/ $\mathrm{AgCl}$; (b) PQS biosynthesis in P. aeruginosa. Anthranilic acid 3 condenses with a $\beta$-keto fatty acid 4 to produce HHQ through the action of the $p q s A B C D E$ operon. The monooxygenase PqsH converts HHQ into PQS; (c) and (d) Monitoring the production of HHQ, PQS and PYO in the bacterial strain P. aeruginosa PA14 in $\mathrm{LB}$ media was carried out over $8 \mathrm{~h}$. Cell density was measured in terms of $\mathrm{OD}_{600 \mathrm{~nm}}$. The bacterial culture was extracted twice with acidified ethyl acetate and MCX SPE, and a given amount of the eluent added to the electrolyte: $50 \mathrm{mM}$ acetate buffer, pH 5.0 with $20 \% \mathrm{ACN}$. All measurements were made in triplicate, using peak area of the analytes response on the BDD electrode vs. $\mathrm{Ag} / \mathrm{AgCl}$. Error bars represent SD $(\mathrm{n}=3)$. The oxidation peaks of $-0.14 \mathrm{~V}$ and $\sim+1.0 \mathrm{~V}$ were presented for PYO and PQS, respectively.

interference, a sputum sample obtained from a paediatric CF patient who was not infected with P. aeruginosa was spiked with known amounts of PYO $(10,20$, and $40 \mu \mathrm{M})$, HHQ $(20,40$, and $80 \mu \mathrm{M})$, and PQS $(40,80$, and $160 \mu \mathrm{M})$. All blank and spiked sputum samples were then extracted twice with chloroform (1:2, v/v sputum sample: chloroform). Importantly, the blank sputum sample did not produce any signature signal, consistent with the absence of $P$. aeruginosa signaling molecules. Therefore, the corresponding DPV exhibited no oxidation peaks. In the case of spiked sputum samples, all the target analytes were detected and recovery values measured were up to $32 \%, 43 \%$, and $58 \%$ for PYO, HHQ, and PQS, respectively. The LOD of PYO, HHQ, and PQS in CF sputum sample using DPV on the bare BDD electrode is $0.15 \mu \mathrm{M}, 0.62 \mu \mathrm{M}$, and $1.25 \mu \mathrm{M}$, respectively $(\mathrm{S} / \mathrm{N}=3)$. In addition, the sputum sample was spiked with $1 \times 10^{5}$ cells of $P$. aeruginosa and incubated at $37^{\circ} \mathrm{C}$ for several days to promote bacterial growth. The sputum sample was then extracted with chloroform, dried with a rotary evaporator and re-dispersed with ACN. The DPVs were recorded by adding a certain amount of the reconstituted sample into $50 \mathrm{mM}$ acetate buffer ( $\mathrm{pH}$ 5.0) containing 20\% ACN. Figure 7 compares the DPV profiles of the blank and P. aeruginosa spiked sputum samples incubated for $3 \mathrm{~d}$ and $11 \mathrm{~d}$. No peak obtained at the negative potential on the DPV curve of the sputum sample that was incubated for $3 \mathrm{~d}$ indicates the absence or a non-detectable amount of PYO. However, a clear peak at $-0.14 \mathrm{~V}$ was exhibited on the DPV curve of the sample incubated for $11 \mathrm{~d}$. A concentration of $2.8 \mu \mathrm{M}$, $7.2 \mu \mathrm{M}$, and $10.4 \mu \mathrm{M}$ was calculated for PYO, HHQ, and PQS, respectively in spiked CF sputum sample incubated for $11 \mathrm{~d}$. The target analytes were not detected in the sputum sample incubated for $3 \mathrm{~d}$, likely due to a lower concentration of HHQ and PQS at this stage ${ }^{41}$ and the matrix effect.

\section{Conclusions}

The BDD electrode was successfully used for simultaneous determination of PYO, HHQ and PQS in both standard mixtures and microbial P. aeruginosa strain PA14 using a conventional and rapid extraction method. The production of three target signals in P. aeruginosa PA14 over $8 \mathrm{~h}$ was monitored, illustrating the selectivity of BDD electrode with the obtained results in agreement with previous reports ${ }^{35,36,38}$. Most importantly, the application 


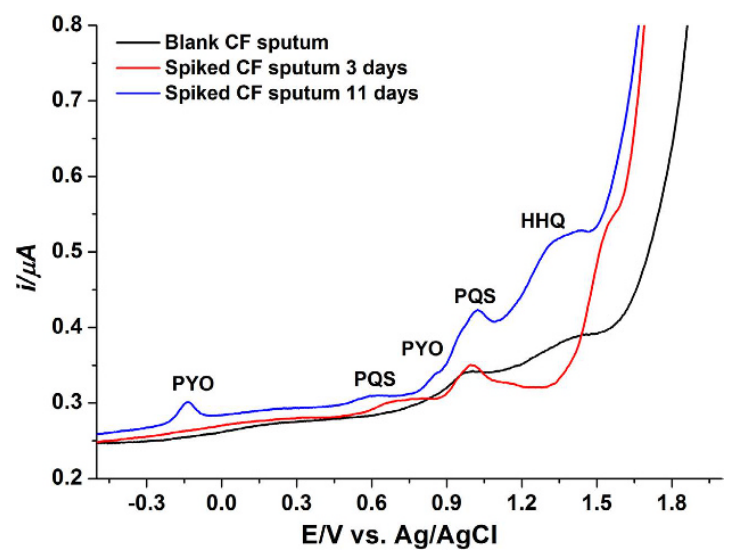

Figure 7. Clinical sample analysis. DPV of a CF sputum sample cultured with $P$. aeruginosa and incubated at $37^{\circ} \mathrm{C}$ for 3 and $11 \mathrm{~d}$. A small amount of sputum extract was added to the electrochemical cell containing $50 \mathrm{mM}$ acetate buffer, pH 5.0 with 20\% ACN and detected on the BDD electrode vs. $\mathrm{Ag} / \mathrm{AgCl}$.

of the optimized method was extended to the CF sputum sample cultured with $P$. aeruginosa. In this regard, the importance of including the three biomarkers is highlighted by the recent suggestion that HHQ predominates over PQS in CF sputum samples ${ }^{42}$.

\section{Methods}

Chemicals and materials. All the reagents were of the analytical grade with the highest purity, and aqueous solutions were prepared in deionized water with a resistivity of $18.2 \mathrm{M} \Omega . \mathrm{cm}$ (Millipore, Ireland). Pyocyanin, acetic acid, sodium acetate anhydrous, sodium phosphate dibasic, sodium phosphate monobasic, acetonitrile, methanol, 2-propanol, phosphoric acid, formic acid, ammonium formate, chloroform, and ethyl acetate were purchased from Sigma-Aldrich (Dublin, Ireland). Micro polish alumina powder $(0.05 \mu \mathrm{m}$ and $0.3 \mu \mathrm{m})$, nylon and masterTex polishing cloths were purchased from Buehler (Coventry, UK). Acetate buffer (50 mM, pH 4.0-6.0, with $20 \% \mathrm{ACN}$ ) and phosphate buffer $(50 \mathrm{mM}, \mathrm{pH} 7.0$, with $20 \% \mathrm{ACN})$ were employed as the supporting electrolytes. The stock solutions of $2 \mathrm{mM}$ PQS, HHQ and PYO were prepared in ACN freshly before use. ACN was used to support solubility of the three target analytes. The solid-phase extraction was performed using the Oasis mixed-mode cation exchange cartridge MCX SPE 1 cc (30 mg) from Waters (Dublin, Ireland).

Apparatus. Cyclic voltammetry (CV), differential pulse voltammetry (DPV) and amperometric measurement $(\mathrm{I} / \mathrm{t})$ were performed using a CHI1040A electrochemical workstation (CH Instrument, Austin, TX). The electrochemical cell consists of a BDD electrode as a working electrode ( $3 \mathrm{~mm}$ diameter, $0.1 \%$ doped boron, Windsor Scientific, Slough Berkshire, UK), an $\mathrm{Ag} / \mathrm{AgCl}(3 \mathrm{M} \mathrm{KCl})$ as a reference electrode (BASi Analytical Instruments, West Layette, IN) and a Pt wire as a counter electrode (Sigma-Aldrich, Dublin, Ireland). The convective transport during the amperometric determination was performed with magnetic stirring at $800 \mathrm{rpm}$. All $\mathrm{pH}$ values of different electrolytes were measured using a $\mathrm{pH}$ meter (a pH 210 microprocessor) which calibrated daily with standard buffer solutions. All measurements were performed at room temperature.

Synthesis of PQS and HHQ. PQS and HHQ were synthesized as described by Pesci et al. ${ }^{43}$ and McGlacken et al. ${ }^{44}$. The resulting products and their purity were confirmed by ${ }^{1} \mathrm{H}$ NMR $(300 \mathrm{MHz})$ and spectra are shown in a previous publication ${ }^{45}$.

Electrode preparation. The BDD electrode was polished with polishing papers (Buehler, UK) and subsequently with alumina (Buehler, UK) until a mirror finish was obtained. After cleaning the electrode with deionized water, the electrode was sonicated in 2-propanol and deionized water for $5 \mathrm{~min}$ and $10 \mathrm{~min}$, respectively. Subsequently, the electrode was cleaned by CV between $-1.0 \mathrm{~V}$ and $+2.0 \mathrm{~V}$ versus $\mathrm{Ag} / \mathrm{AgCl}(3 \mathrm{M} \mathrm{KCl})$ at $100 \mathrm{mV} \mathrm{s}^{-1}$ in $50 \mathrm{mM}$ acetate buffer ( $\mathrm{pH}$ 5.0) until a stable $\mathrm{CV}$ profile was obtained.

Bacterial strains, growth conditions and clinical samples. Bacterial supernatant extracts were obtained using a modified version of the Fletcher protocol ${ }^{2}$. Briefly, overnight cultures of P. aeruginosa PA14 were transferred into fresh Luria-Bertani (LB) broth $\left(\mathrm{OD}_{600 \mathrm{~nm}} 0.01\right)$ and incubated for $7 \mathrm{~h}$ at $37^{\circ} \mathrm{C}$ (total $\left.20 \mathrm{~mL}\right)$. Culture supernatants were obtained by centrifugation at 4000 revolutions per minute (rpm) for 15 min and subsequently filter sterilized using Minisart (Sartorius) $0.2 \mu \mathrm{m}$ filter into a clean centrifuge tube. Extractions using acidified ethyl acetate $(0.01 \%$ (v/v) glacial acetic acid) were performed twice on bacterial cell-free cultures (end-point assays) (1:2, v/v supernatants: acidified ethyl acetate) or whole cell cultures (time-point assays) (1:1, v/v whole cell culture: acidified ethyl acetate). In both assays, the organic phase was evaporated using a rotary evaporator and the residue was dissolved in ACN (end-point assay) and in $0.5 \mathrm{M}$ formic acid pH 2.0 (time-point assay). Solid-phase extraction using MCX SPE was carried out after liquid-liquid extraction for time-point assays. The reconstituted samples were subjected to MCX SPE cartridges pre-conditioned with methanol and deionized water. The cartridges were washed then with $0.5 \mathrm{M}$ formate buffer, $\mathrm{pH} 2.0$ to increase the retention of analytes and 
washed with $100 \%$ methanol to remove neutral interferences. Subsequently, the analytes were eluted using $5 \%$ 4.5 $\mathrm{M}$ ammonium formate in methanol.

Ethics statement and sputum processing. Sputum samples were collected from paediatric patients attending the CF clinic at Cork University Hospital, Ireland. Ethical approval was granted by the Clinical Research Ethics Committee (CREC) for sputum collection and samples were handled in accordance with the approved guidelines. All methods were carried out in accordance with the approved guidelines. Written informed consent from all patients/guardians was obtained for acquisition and analysis outlined in this study. Patient sputum samples were inoculated with $1 \times 10^{5}$ cells of $P$. aeruginos $a$ and incubated at $37^{\circ} \mathrm{C}$ for 3 and $11 \mathrm{~d}$, respectively. CF patient samples were extracted twice with chloroform (1:2, v/v sputum sample: chloroform). As mentioned above, the organic phase was evaporated using a rotary evaporator and the residue was dissolved in ACN.

\section{References}

1. Lazdunski, A. M., Ventre, I. \& Sturgis, J. N. Regulatory circuits and communication in Gram-negative bacteria. Nat Rev Microbiol 2, 581-592 (2004).

2. Fletcher, M. P., Diggle, S. P., Camara, M. \& Williams, P. Biosensor-based assays for PQS, HHQ and related 2-alkyl-4-quinolone quorum sensing signal molecules. Nat Protoc 2, 1254-1262 (2007).

3. Ortori, C. A. et al. Simultaneous quantitative profiling of N-acyl-L-homoserine lactone and 2-alkyl-4(1H)-quinolone families of quorum-sensing signaling molecules using LC-MS/MS. Anal Bioanal Chem 399, 839-850 (2011).

4. Dubern, J. F. \& Diggle, S. P. Quorum sensing by 2-alkyl-4-quinolones in Pseudomonas aeruginosa and other bacterial species. Mol Biosyst 4, 882-888 (2008).

5. Fick, R. B. Jr. Pathogenesis of the pseudomonas lung lesion in cystic fibrosis. Chest 96, 158-164 (1989).

6. Muller, C. \& Fetzner, S. A Pseudomonas putida bioreporter for the detection of enzymes active on 2-alkyl-4(1H)-quinolone signalling molecules. Appl Microbiol Biotechnol 97, 751-760 (2013).

7. Bala, A., Gupta, R. K., Chhibber, S. \& Harjai, K. Detection and quantification of quinolone signalling molecule: a third quorum sensing molecule of Pseudomonas aeruginosa by high performance-thin layer chromatography. J Chromatogr B Analyt Technol Biomed Life Sci 930, 30-35 (2013).

8. Webster, T. A. \& Goluch, E. D. Electrochemical detection of pyocyanin in nanochannels with integrated palladium hydride reference electrodes. Lab Chip 12, 5195-5201 (2012).

9. Diggle, S. P. et al. Functional genetic analysis reveals a 2-Alkyl-4-quinolone signaling system in the human pathogen Burkholderia pseudomallei and related bacteria. Chem Biol 13, 701-710 (2006).

10. Roy, P. H. et al. Complete genome sequence of the multiresistant taxonomic outlier Pseudomonas aeruginosa PA7. PLoS One 5, e8842 (2010).

11. Wilson, R. et al. Measurement of Pseudomonas aeruginosa phenazine pigments in sputum and assessment of their contribution to sputum sol toxicity for respiratory epithelium. Infect Immun 56, 2515-2517 (1988).

12. Shang, F. et al. Selective nanomolar detection of dopamine using a boron-doped diamond electrode modified with an electropolymerized sulfobutylether-beta-cyclodextrin-doped poly(N-acetyltyramine) and polypyrrole composite film. Anal Chem 81, 4089-4098 (2009)

13. Diggle, S. P., Fletcher, M. P., Camara, M. \& Williams, P. Detection of 2-alkyl-4-quinolones using biosensors. Methods Mol Biol 692, 21-30 (2011).

14. Fletcher, M. P. et al. A dual biosensor for 2-alkyl-4-quinolone quorum-sensing signal molecules. Environ Microbiol 9, 2683-2693 (2007).

15. Zhou, L. et al. Detection of the Pseudomonas Quinolone Signal (PQS) by cyclic voltammetry and amperometry using a boron doped diamond electrode. Chem Commun 47, 10347-10349 (2011).

16. Shang, F. et al. One step preparation and electrochemical analysis of IQS, a cell-cell communication signal in the nosocomial pathogen Pseudomonas aeruginosa. Bioorg Med Chem Lett 24, 4703-4707 (2014).

17. Vukomanovic, D. V. et al. Analysis of pyocyanin from Pseudomonas aeruginosa by adsorptive stripping voltammetry. J Pharmacol Toxicol Methods 36, 97-102 (1996).

18. Bukelman, O. et al. Electrochemical analysis of quorum sensing inhibition. Chem Commun 28, 2836-2838 (2009).

19. Webster, T. A., Sismaet, H. J., Chan, I. P. \& Goluch, E. D. Electrochemically monitoring the antibiotic susceptibility of Pseudomonas aeruginosa biofilms. Analyst 140, 7195-7201 (2015).

20. Webster, T. A., Sismaet, H. J., Conte, J. L., Chan, I. P. \& Goluch, E. D. Electrochemical detection of Pseudomonas aeruginosa in human fluid samples via pyocyanin. Biosens Bioelectron 60, 265-270 (2014).

21. Webster, T. A., Sismaet, H. J., Sattler, A. F. \& Goluch, E. D. Improved monitoring of P. aeruginosa on agar plates. Anal Methods-Uk 7, 7150-7155 (2015).

22. Sismaet, H. J., Webster, T. A. \& Goluch, E. D. Up-regulating pyocyanin production by amino acid addition for early electrochemical identification of Pseudomonas aeruginosa. Analyst 139, 4241-4246 (2014).

23. Kim, E., Gordonov, T., Bentley, W. E. \& Payne, G. F. Amplified and in situ detection of redox-active metabolite using a biobased redox capacitor. Anal Chem $\mathbf{8 5}, 2102-2108$ (2013).

24. Bellin, D. L. et al. Integrated circuit-based electrochemical sensor for spatially resolved detection of redox-active metabolites in biofilms. Nat Commun 5, 3256 (2014).

25. Sharp, D., Gladstone, P., Smith, R. B., Forsythe, S. \& Davis, J. Approaching intelligent infection diagnostics: Carbon fibre sensor for electrochemical pyocyanin detection. Bioelectrochemistry 77, 114-119 (2010).

26. Webster, T. A., Sismaet, H. J. \& Goluch, E. D. Amperometric Detection Of Pyocyanin In Nanofluidic Channels. Nano LIFE 03, 1340011 (2013).

27. Oziat, J., Elsen, S., Owens, R. M., Malliaras, G. G. \& Mailley, P. Electrochemistry provides a simple way to monitor Pseudomonas aeruginosa metabolites. Conf Proc IEEE Eng Med Biol 7522-7525 (2015).

28. Seviour, T. et al. Voltammetric profiling of redox-active metabolites expressed by Pseudomonas aeruginosa for diagnostic purposes. Chem Commun 51, 3789-3792 (2015).

29. Luong, J. H. T., Male, K. B. \& Glennon, J. D. Boron-doped diamond electrode: synthesis, characterization, functionalization and analytical applications. Analyst 134, 1965-1979 (2009).

30. Shang, F., Liu, Y., Hrapovic, S., Glennon, J. D. \& Luong, J. H. T. Selective detection of dopamine using a combined permselective film of electropolymerized (poly-tyramine and poly-pyrrole-1-propionic acid) on a boron-doped diamond electrode. Analyst 134, 519-527 (2009).

31. Sheng, Z. H. et al. Electrochemical sensor based on nitrogen doped graphene: simultaneous determination of ascorbic acid, dopamine and uric acid. Biosens Bioelectron 34, 125-131 (2012).

32. Huang, K. J. et al. Electrochemical biosensor based on silver nanoparticles-polydopamine-graphene nanocomposite for sensitive determination of adenine and guanine. Talanta 114, 43-48 (2013). 
33. Temerk, Y. M. \& Ibrahim, H. S. M. Individual and Simultaneous Square Wave Voltammetric Determination of the Anticancer Drugs Emodin and Irinotecan at Renewable Pencil Graphite Electrodes. J Brazil Chem Soc 24, 1669-1678 (2013).

34. Canevari, T. C., Raymundo-Pereira, P. A., Landers, R., Benvenutti, E. V. \& Machado, S. A. Sol-gel thin-film based mesoporous silica and carbon nanotubes for the determination of dopamine, uric acid and paracetamol in urine. Talanta 116, 726-735 (2013).

35. Deziel, E. et al. Analysis of Pseudomonas aeruginosa 4-hydroxy-2-alkylquinolines (HAQs) reveals a role for 4-hydroxy-2heptylquinoline in cell-to-cell communication. Proc Natl Acad Sci USA 101, 1339-1344 (2004).

36. Lepine, F., Deziel, E., Milot, S. \& Rahme, L. G. A stable isotope dilution assay for the quantification of the Pseudomonas quinolone signal in Pseudomonas aeruginosa cultures. Biochim Biophys Acta 1622, 36-41 (2003).

37. Drees, S. L. \& Fetzner, S. PqsE of Pseudomonas aeruginosa Acts as Pathway-Specific Thioesterase in the Biosynthesis of Alkylquinolone Signaling Molecules. Chem Biol 22, 611-618 (2015).

38. Dietrich, L. E., Price-Whelan, A., Petersen, A., Whiteley, M. \& Newman, D. K. The phenazine pyocyanin is a terminal signalling factor in the quorum sensing network of Pseudomonas aeruginosa. Mol Microbiol 61, 1308-1321 (2006).

39. Palmer, K. L., Mashburn, L. M., Singh, P. K. \& Whiteley, M. Cystic fibrosis sputum supports growth and cues key aspects of Pseudomonas aeruginosa physiology. J Bacteriol 187, 5267-5277 (2005).

40. Sanders, N. N. et al. Cystic fibrosis sputum: a barrier to the transport of nanospheres. Am J Respir Crit Care Med 162, 1905-1911 (2000).

41. Barr, H. L. et al. Pseudomonas aeruginosa quorum sensing molecules correlate with clinical status in cystic fibrosis. Eur Respir J 46, 1046-1054 (2015).

42. Quinn, R. A. et al. Microbial, host and xenobiotic diversity in the cystic fibrosis sputum metabolome. ISME J 10, 1-16 (2015).

43. Pesci, E. C. et al. Quinolone signaling in the cell-to-cell communication system of Pseudomonas aeruginosa. Proc Natl Acad Sci USA 96, 11229-11234 (1999).

44. McGlacken, G. P. et al. Synthesis of 3-halo-analogues of HHQ, subsequent cross-coupling and first crystal structure of Pseudomonas quinolone signal (PQS). Tetrahedron Letters 51, 5919-5921 (2010).

45. Zhou, L. et al. Analysis of Pseudomonas quinolone signal and other bacterial signalling molecules using capillaries coated with highly charged polyelectrolyte monolayers and boron doped diamond electrode. J Chromatogr A 1251, 169-175 (2012).

\section{Acknowledgements}

This research was financially supported by SFI/EI Technology Innovation Development Award (TIDA) (SFI/12/ TIDA/B2405). FOG acknowledges the grants awarded by the European Commission (FP7-PEOPLE-2013ITN, 607786; FP7-KBBE-2012-6, CP-TP-312184; FP7-KBBE-2012-6, 311975; OCEAN 2011-2, 287589; Marie Curie 256596; EU-634486), Science Foundation Ireland (SSPC-2, 12/RC/2275; 13/TIDA/B2625; 12/TIDA/ B2411; 12/TIDA/B2405; 14/TIDA/2438), the Department of Agriculture and Food (FIRM/RSF/CoFoRD; FIRM 08/RDC/629; FIRM 1/F009/MabS; FIRM 13/F/516), the Irish Research Council for Science, Engineering and Technology (PD/2011/2414; GOIPG/2014/647), the Health Research Board/Irish Thoracic Society (MRCG2014-6), the Marine Institute (Beaufort award C2CRA 2007/082) and Teagasc (Walsh Fellowship 2013). JDG thanks the Science Foundation Ireland (08/SRC/B1412) for research funding of the Irish Separation Science Cluster (ISSC) under the Strategic Research Cluster Programme. GPM acknowledges supports by the Science Foundation Ireland (SFI/12/IP/1315, SFI/09/RFP/CHS2353 and SSPC2 12/RC/2275), the Irish Research Council (GOIPG/2013/336) and UCC for a Strategic Research Fund Ph.D. Studentship.

\section{Author Contributions}

A.B. performed the experiments; A.B. and F.S. wrote the first manuscript; F.J.R. and F.O'.G. supplied biological and clinical samples; E.Ó.M. and S.L.C. synthesized PQS and HHQ; L.Z. started initial detection of PQS and HHQ; A.B., F.S. and F.J.R. analyzed the data; F.J.R., J.H.T.L., F.O'G., G.P.M. and J.D.G., as senior authors, directed the research and contributed substantially to revisions.

\section{Additional Information \\ Competing financial interests: The authors declare no competing financial interests.}

How to cite this article: Buzid, A. et al. Molecular Signature of Pseudomonas aeruginosa with Simultaneous Nanomolar Detection of Quorum Sensing Signaling Molecules at a Boron-Doped Diamond Electrode. Sci. Rep. 6, 30001; doi: 10.1038/srep30001 (2016).

This work is licensed under a Creative Commons Attribution 4.0 International License. The images or other third party material in this article are included in the article's Creative Commons license, unless indicated otherwise in the credit line; if the material is not included under the Creative Commons license, users will need to obtain permission from the license holder to reproduce the material. To view a copy of this license, visit http://creativecommons.org/licenses/by/4.0/ 